\title{
An Orbital Exchange Calculation of Chemical Bonding in Metals
}

\author{
Paul B. Merrithew ${ }^{\mathrm{a}}$ \\ PO Box 120, Amherst, New Hampshire 03031-0120 USA
}

\begin{abstract}
This work calculates the chemical bonds in lithium metal and beryllium metal using the orbital exchange method, a method that recognizes that the two electrons of a bonding pair cannot be completely distinguished when their orbitals overlap to bond. Since in metals there is no preferred bond direction, the symmetry axes of the lattice are chosen as the bonding axes. The calculations sum the primary, secondary and many tertiary bonds along these axes. The bond length and bond energy results are in agreement with the observed values with bond energies accurate to $0.2 \mathrm{eV}$ or better and bond lengths to $0.02 \AA$. The bond lengths are found at the point where the total bond overlap equals 1.0.

These results are compared with the orbital exchange calculations of bonding in diamond, a nonconductor, and graphite, a semiconductor. An uncomplicated explanation for the difference in electrical properties emerges. The conductor, lithium metal, has a $2 \mathrm{~s}$ bonding orbital which bonds equally in both directions along all axes providing for the continuous flow of electrons. The nonconductor, diamond, has a directional s p hybrid type bonding orbital which bonds in one direction along a single axis, preventing the flow of electrons from atom to atom.
\end{abstract}

\section{INTRODUCTION}

Orbital exchange calculations ${ }^{1}$ of chemical bonding do not assume that the electrons of the chemical bonding electron pair can be unambiguously identified with either the left hand or right hand of the bonding atoms when their orbitals overlap to bond. That the two electrons of the bonding electron pair cannot be unambiguously identified when overlap occurs has implications beyond a straightforward reduction in kinetic energy. Firstly, an atomic orbital, or hybrid orbital, can bond with orbitals on multiple atoms (once removed atoms or atoms in the opposite directions) given that coincident overlap is taken into account and the total overlap along a given axis in a given direction does not exceed 1.0. Secondly, the energy required to meet orthogonality requirements is a function the degree of ambiguity and, for example in diatomic molecules, at overlap $=1.0$, reaches a maximum of 0.5 of the total energy to orthogonalize. Thirdly, since the degree of ambiguity reaches 0.5 , the range of possible values for the hybrid orbital coefficients $\mathrm{fs}_{\mathrm{b}}$ and $\mathrm{fp}_{\mathrm{b}}$ is extended. For example, the configuration $2 \mathrm{~s} 2 \mathrm{p}_{\mathrm{z}}{ }^{3}$ can give rise to four hybrid orbitals with $\mathrm{fs}_{\mathrm{b}} \mathrm{f} \mathrm{s}_{\mathrm{b}}=0.5$.

The purpose of this paper is to apply orbital exchange methods to the study of chemical bonding in metals and to compare these results to the results for nonmetals. This work calculates the chemical bonds in lithium metal and beryllium metal and compares them with previous orbital exchange calculations of bonding in diamond, a nonconductor, and graphite, a semiconductor.

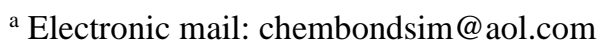




\section{ORBITAL EXCHANGE METHODS}

Orbital exchange calculations ${ }^{1}$ are done numerically with the bonding orbitals represented in huge spatial arrays. The approach used to calculate kinetic energy and overlap was described previously. When an atom presents a bonding orbital to the opposite atom changes are made to meet the orthogonality requirements: the bonding orbital is made orthogonal to the "core" electrons on the opposite atom and the not-bonding electron orbitals are changed/reconfigured to be orthogonal to the bonding orbital from the opposite atom. The methods used to meet the orthogonality requirements and calculate the associated energy were described previously. The methods used to calculate secondary/tertiary bonding in polyatomic molecules have also been described.

\section{SECONDARY/TERTIARY BONDING IN METALS}

The bonding orbitals in poly-atomic molecules and metals bond, not only to bonding orbitals on the closest atom, but also to overlapping bonding orbitals on other atoms. In polyatomic molecules there are primary bonds to the nearest atoms, weaker secondary bonds to atoms which have their primary bond to other atoms and etc. In metals there are primary bonds to the nearest neighbors, secondary bonds to the next-nearest neighbors and etc. The difference between metals and poly-atomics lies in the directionality of the bond. The bonding orbitals in poly-atomics are directional (sp hybrid orbitals, for example). The bonding orbitals in metals are at least partially omni-directional (s orbitals, for example).

Metals differ from poly-atomics in the selection of the bonding axes. For poly-atomics the bond axis is the axis of the primary bond. Metals do not possess a preferred bond direction. In metals, the symmetry axes of the lattice are chosen as the bonding axes.

In the summation of the secondary, tertiary, etc. contributions to the total bond, coincident, redundant bonds must be excluded. For poly-atomic molecules, secondary bonding is reduced by the extent of primary bonding, and the tertiary by the extent of primary and secondary and etc. In metals, the bonding orbitals are omni-directional and no single bond component takes precedence. Therefore, to exclude coincident overlaps, all overlap contributions to the bond are reduced to the theoretical maximum extent of overlap along a given axis (overlap $=1.0$ ) less the current overlap contribution.

The calculation of overlap in metals is as follows. Each atom's incremental contribution to the total overlap along the chosen axis is determined. An incremental (_inc) overlap component along the major axis, overlapinc_z, is:

$$
\text { overlapinc_z }=\cos ^{2} \theta \text { overlapinc }
$$

where $\theta$ is the angle between the major axis and the bond axis. Fraction_bonding is adjusted to exclude coincident overlaps:

$$
\begin{gathered}
\text { fraction_bonding } g_{\text {adj_inc }}=\left(1-\left(1-\text { overlap }_{\text {adj_inc }}\right) /\left(1+1-\text { overlap }_{\text {adj_inc }}\right)\right) \\
\left(\text { overlap }_{\text {inc_z }} /\left(1+\text { overlap }_{\text {inc_z }}\right)\right) .
\end{gathered}
$$

The incremental overlap contribution to the total overlap, the adjusted overlap increment, overlapadj_inc, is: 


$$
\text { overlap }_{\text {adj_inc }}=\text { fraction_bonding } \text { adj_ind }_{\text {ind }}\left(1 \text {-fraction_bonding }{ }_{\text {adj_inc }}\right) \text {. }
$$

The quantity, overlapadj_inc is initially estimated, with the final value obtained by iterating (2) and (3) several times. The overlap subtotal, overlapsubtotal, is:

$$
\text { overlap }_{\text {subtotal }}=\text { overlap }_{\text {previous_subtotal }}+\text { overlap }_{\text {adj_inc }} \text {. }
$$

The energy associated with core orthogonalization of a primary bonding orbital with the core electrons of the secondary atom is discussed in a previous paper ${ }^{1}$. Secondary potential energy terms are calculated in the same manner as those of the primary terms.

\section{ATOMIC ORBITALS AND ORBITAL SCALE FACTORS}

For beryllium (Be) and lithium ( $\mathrm{Li}$ ), the atomic orbitals of Duncanson and Coulson ${ }^{2}$ have been used. The effective nuclear charge [or orbital scale factor] for $2 \mathrm{~s}$ and $2 p$ electrons (The quantities Duncanson and Coulson call $\mu$ and $\mu \mathrm{c}$.) are increased by factors (called fact herein) ranging from 1.03 to 1.05 . Slight contractions of atomic orbitals are favorable because they give rise to bond strength increases greater than the energy required to contract the orbital. Table 1 gives the approximate energy impact of small changes to the effective nuclear charge.

Table 1. Estimated Energy (eV) Associated with Orbital Scale Factor

\begin{tabular}{c|cccccc|}
\multicolumn{7}{c}{ Factors } \\
Atom & 1.01 & 1.02 & 1.03 & 1.04 & 1.05 & 1.055 \\
\hline $\mathrm{Li}$ & & & & & 0.01 & 0.02 \\
$\mathrm{Be}$ & & & 0.01 & 0.03 & 0.06 & 0.09 \\
\cline { 3 - 6 }
\end{tabular}

\section{RESULTS}

The results of the calculation of the chemical bonds in $\mathrm{Be}$ and $\mathrm{Li}$ metal are shown in Table 2. Measured values for bond energy ${ }^{3}$ and bond lengths ${ }^{4}$ are derived from data in the CRC Handbook. The $\mathrm{s}$ to $\mathrm{p}$ energy for Be has been estimated at $2.6 \mathrm{eV}$. The calculated bond energy in $\mathrm{Be}$ metal has a significant uncertainty because of the uncertainty in the $\mathrm{s}$ to $\mathrm{p}$ energy for Be. A precise value for the $\mathrm{s}$ to $\mathrm{p}$ energy in Be compounds has not been obtained because few $\mathrm{Be}$ compounds have been investigated. The bond lengths in Be and $\mathrm{Li}$ are uncertain by about $0.02 \AA$ because the bond energy changes relatively slowly with changes in in the orbital scale factor at overlap=1.0. The bond lengths and bond energies for $\mathrm{Li}$ and $\mathrm{Be}$ metal are found at the point where overlap equals 1.0. 
Table 2. Bonding Calculations Results for Lithium and Beryllium Metal

\begin{tabular}{|c|c|c|c|c|c|}
\hline Bond & $\begin{array}{c}\text { Bond } \\
\text { Energy/eV }\end{array}$ & $\begin{array}{c}\text { Bond } \\
\text { Length/Å }\end{array}$ & $\begin{array}{c}\text { Configurations } \\
\text { (1s }{ }^{2} \text { omitted) }\end{array}$ & Structure & Bonds \\
\hline $\begin{array}{l}\text { LiLi/Li } \\
\text { Metal }\end{array}$ & $\begin{array}{c}\text { observed } \\
1.66 \\
\text { calculated } \\
1.72\end{array}$ & $\begin{array}{c}\text { observed } \\
3.04 \\
\text { calculated } \\
3.04 \pm 0.02 \\
\\
\text { fact }(\mathrm{Li})= \\
1.03\end{array}$ & $2 \mathrm{~s}$ & $\begin{array}{c}\text { body centered } \\
\text { cubic (bcc) } \\
8 \text { nearest } \\
\text { neighbors, } \\
6 \text { next, } 12 \text { next, } \\
24 \text { next,8 next, } \\
6 \text { next,24 next, } \\
32 \text { next,6 next }\end{array}$ & $\begin{array}{c}\sigma \\
\sigma_{s-s} \\
\text { Coincident overlaps are } \\
\text { excluded from the overlap } \\
\text { calculation. } \\
\text { Since Li bonds are } \\
\text { omnidirectional, Li metal is a } \\
\text { conductor }\end{array}$ \\
\hline $\begin{array}{l}\mathrm{BeBe} / \mathrm{Be} \\
\text { Metal }\end{array}$ & $\begin{array}{c}\text { observed } \\
3.40 \\
\text { calculated } \\
3.35 \pm 0.2 \\
\text { (assumes } \\
\text { stop }=2.59 \text { ) }\end{array}$ & $\begin{array}{c}\text { observed } \\
2.25 \\
\text { calculated } \\
2.24 \pm 0.02 \\
\\
\text { fact }(\mathrm{Be})= \\
1.05\end{array}$ & $\begin{array}{c}2 \mathrm{~s} 2 \mathrm{p} \\
2 \mathrm{~s} \text { and }(1 / 3 \text { along } \\
\text { each axis) } 2 \mathrm{sp} \\
\text { bonding } \\
\text { orbitals } \mathrm{fs}_{\mathrm{b}} \cdot \mathrm{fs}_{\mathrm{b}}=0.5 \\
2 \mathrm{~s} \text { is promoted to } \\
2 \mathrm{p} \text { to permit } \\
\text { bonding }\end{array}$ & $\begin{array}{l}\text { hexagonal close } \\
\text { packed (hcp) } \\
12 \text { nearest } \\
\text { neighbors, } \\
6 \text { next, } 2 \text { next, } \\
12 \text { next, } 12 \text { next, } \\
6 \text { next, } 12 \text { next }\end{array}$ & $\begin{array}{c}\sigma \\
2 / 3 \cdot 2 / 3 \sigma_{s-s}, 2 \cdot 1 / 3 \cdot 2 / 3 \sigma_{\text {sp-s }} \\
1 / 3 \cdot 1 / 3 \sigma_{\text {sp-sp }} \\
\text { Since the sp bonding orbital } \\
\text { introduces direction to the } \\
\text { bond, Be metal's conductivity } \\
\text { is limited with respect to Li. }\end{array}$ \\
\hline
\end{tabular}

\section{A. Lithium Metal}

Lithium metal has a body centered cubic structure $(\mathrm{bcc})^{5}$. A drawing of this structure is given by Wells ${ }^{6}$. A detailed breakdown of the Li metal calculation is presented in Table 3 . The calculation encompasses the primary, secondary and seven tertiary contributions to the bond. The 2 s bonding orbital of Li overlaps completely (overlap $=1.0$ ), in both directions, along the component axes. In the absence of nuclear vibrations or dislocations, there is no resistance to the passage of electrons. This view is consistent with that of the free electron model of Sommerfeld ${ }^{7}$.

\section{Table 3. Components of the Li metal Calculation at $3.043 \AA$ (Energy in electron volts) (Actual calculated bond length is $3.035 \AA$.)}

The configuration of Lithium is $1 \mathrm{~s}^{2} 2 \mathrm{~s}$. Lithium has a body-centered cubic $(\mathrm{bcc})$ structure. The $2 \mathrm{~s}$ orbital scale factor, fact ${ }_{2 s}=1.03$. The terminology used here is that of reference 1.

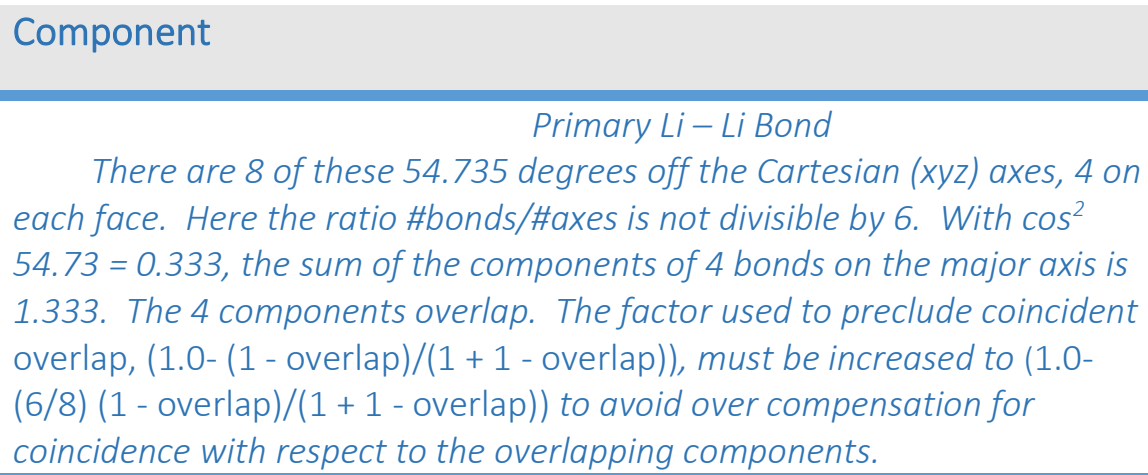

Primary Li- Li Bond

There are 8 of these 54.735 degrees off the Cartesian (xyz) axes, 4 on each face. Here the ratio \#bonds/\#axes is not divisible by 6 . With $\cos ^{2}$

$54.73=0.333$, the sum of the components of 4 bonds on the major axis is

1.333. The 4 components overlap. The factor used to preclude coincident

overlap, (1.0- (1 - overlap)/(1 + 1 - overlap)), must be increased to (1.0-

(6/8) (1 - overlap)/(1 1 - overlap)) to avoid over compensation for 


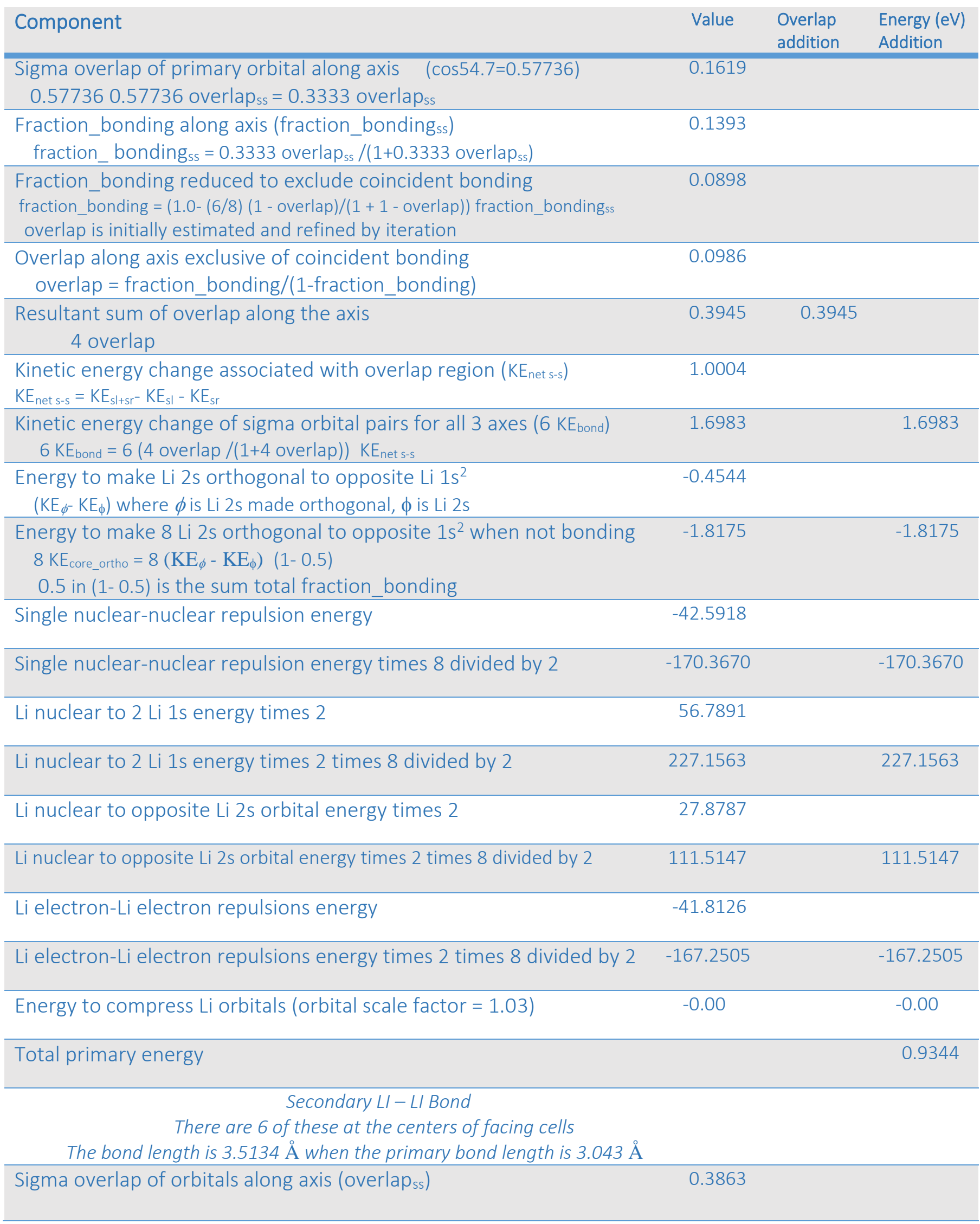




\begin{tabular}{|c|c|c|c|}
\hline Component & Value & $\begin{array}{l}\text { Overlap } \\
\text { addition }\end{array}$ & $\begin{array}{l}\text { Energy (eV) } \\
\text { Addition }\end{array}$ \\
\hline $\begin{array}{l}\left.\text { Fraction_bonding along axis (fraction_bonding }{ }_{s s}\right) \\
\text { fraction_bonding } \\
\text { ss }=\text { overlap }_{\text {ss }} /\left(1+\text { overlap }_{s s}\right)\end{array}$ & 0.2787 & & \\
\hline $\begin{array}{l}\text { Fraction_bonding exclusive of coincident bonding } \\
\text { fraction_bonding }=(1.0-(1-\text { overlap }) /(1+1 \text { - overlap })) \text { fraction_bonding } \\
\text { overlap is initially estimated and refined by iteration }\end{array}$ & 0.1532 & & \\
\hline $\begin{array}{l}\text { Overlap along axis exclusive of coincident bonding } \\
\text { overlap = fraction_bonding/(1-fraction_bonding) }\end{array}$ & 0.1809 & 0.1809 & \\
\hline $\begin{array}{l}\left.\text { Kinetic energy change associated with overlap region ( } K E_{n e t s-s}\right) \\
K E_{n e t s-s}=K E_{s \mid+s r}-K E_{s \mid}-K E_{s r}\end{array}$ & 0.7697 & & \\
\hline $\begin{array}{l}\text { Kinetic energy change of sigma orbital pairs for all } 3 \text { axes }\left(6 \mathrm{KE}_{\text {bond }}\right) \\
\left.\quad 6 \mathrm{KE}_{\text {bond }}=6 \text { (overlap } /(1+\text { total_overlap })\right) \mathrm{KE}_{\text {net s-s }} \\
\text { Total_overlap = overlap + sum of previous overlaps }\end{array}$ & 0.5302 & & 0.5302 \\
\hline $\begin{array}{l}\text { Energy to make Li } 2 \text { s orthogonal to opposite Li } 1 s^{2} \\
\left(K E_{\phi^{-}} K E_{\phi}\right) \text { where } \phi \text { is Li } 2 \text { s made orthogonal, } \phi \text { is Li } 2 s\end{array}$ & -0.1990 & & \\
\hline $\begin{array}{l}\text { Energy to make } 6 \mathrm{Li} 2 \mathrm{~s} \text { orthogonal to opposite } 1 \mathrm{~s}^{2} \text { when not bonding } \\
6 \mathrm{KE}_{\text {core_ortho }}=6\left(\mathrm{KE}_{\phi}-\mathrm{KE}_{\phi}\right)(1-0.5) \\
0.5 \text { in (1- } 0.5) \text { is the sum total fraction_bonding }\end{array}$ & -0.5970 & & -0.5970 \\
\hline Single nuclear-nuclear repulsion energy & -36.8856 & & \\
\hline Single nuclear-nuclear repulsion energy times 6 divided by 2 & -110.6567 & & -110.6567 \\
\hline Li nuclear to 2 Li 1 s energy times 2 & 49.1808 & & \\
\hline Li nuclear to 2 Li 1s energy times 2 times 6 divided by 2 & 147.5424 & & 147.5424 \\
\hline Li nuclear to opposite Li 2s orbital energy times 2 & 24.4033 & & \\
\hline Li nuclear to opposite Li 2s orbital energy times 2 times 6 divided by 2 & 73.2100 & & 73.2100 \\
\hline Li electron-Li electron repulsions energy & -36.5495 & & \\
\hline Li electron-Li electron repulsions energy times 6 divided by 2 & -109.6486 & & -109.6486 \\
\hline Total secondary energy & & & 0.3804 \\
\hline
\end{tabular}

Tertiary \#1 Li- Li Bond

There are $4 \times 6$ of these at the centers of cells sharing an edge

(all common to 2 axes).

These are 45 degrees off the Cartesian axes

The bond length is $4.9697 \AA$ when the primary bond length is $3.043 \AA$

Sigma overlap of orbitals along axis 0.0812

0.70710 .7071 overlap $_{\mathrm{ss}}=0.5$ overlap $_{\mathrm{ss}}$

Fraction_bonding along axis (fraction_bonding ss $_{\text {S }} \quad 0.0751$

fraction_bonding ${ }_{s s}=$ overlap $_{\text {ss }} /\left(1+\right.$ overlap $\left._{\text {ss }}\right)$ 


\begin{tabular}{|c|c|c|c|}
\hline Component & Value & $\begin{array}{l}\text { Overlap } \\
\text { addition }\end{array}$ & $\begin{array}{l}\text { Energy (eV) } \\
\text { Addition }\end{array}$ \\
\hline $\begin{array}{l}\text { Fraction_bonding exclusive of coincident bonding } \\
\text { fraction_bonding }=(1.0-(1-\text { overlap }) /(1+1 \text { - overlap })) \text { fraction_bonding } \\
\text { overlap is initially estimated and refined by iteration }\end{array}$ & 0.0383 & & \\
\hline $\begin{array}{l}\text { Overlap along axis exclusive of coincident bonding } \\
\text { overlap = fraction_bonding/(1-fraction_bonding) }\end{array}$ & 0.0398 & & \\
\hline $\begin{array}{l}\text { Sum of overlap for } 4 \text { atoms along each axis } \\
4 \text { overlap }\end{array}$ & 0.1593 & 0.1593 & \\
\hline $\begin{array}{l}\left.\text { Kinetic energy change associated with overlap region ( } K E_{\text {net s-s }}\right) \\
K E_{n e t s-s}=K E_{s l+s s}-K E_{s l}-K E_{s r}\end{array}$ & 0.3246 & & \\
\hline $\begin{array}{l}\text { Kinetic energy change of sigma orbital pairs for all } 3 \text { axes }\left(6 \mathrm{KE}_{\text {bond }}\right) \\
\left.6 \mathrm{KE}_{\text {bond }}=6 \text { ( } 4 \text { overlap } /(1+\text { total_overlap })\right) \mathrm{KE}_{\text {net s-s }} \\
\text { Total_overlap }=4 \text { overlap + sum of previous overlaps }\end{array}$ & 0.1789 & & 0.1789 \\
\hline $\begin{array}{l}\text { Energy to make Li } 2 \text { s orthogonal to opposite Li } 1 s^{2} \\
\left(K_{\phi^{-}} K E_{\phi}\right) \text { where } \phi \text { is Li } 2 \text { s made orthogonal, } \phi \text { is Li } 2 s\end{array}$ & -0.0101 & & \\
\hline $\begin{array}{l}\text { Energy to make } 12 \mathrm{Li} 2 \mathrm{~s} \text { orthogonal to opposite } 1 \mathrm{~s}^{2} \text { when not } \\
\text { bonding } \\
12 \mathrm{KE}_{\text {core_ortho }}=12\left(\mathrm{KE}_{\phi}-\mathrm{KE}_{\phi}\right)(1-0.5) \\
\quad 0.5 \text { in }(1-0.5) \text { is the sum total fraction_bonding }\end{array}$ & -0.0604 & & -0.0604 \\
\hline Single nuclear-nuclear repulsion energy times 12 divided by 2 & -156.4627 & & -156.4627 \\
\hline Li nuclear to 2 Li 1s energy times 2 times 12 divided by 2 & 208.6172 & & 208.6172 \\
\hline Li nuclear to opposite Li 2s orbital energy times 2 times 12 divided by 2 & 104.2641 & & 104.2641 \\
\hline Li electron-Li electron repulsions energy times 12 divided by 2 & -156.3143 & & -156.3143 \\
\hline Total tertiary \#1 energy & & & 0.2228 \\
\hline $\begin{array}{l}\text { Tertiary \#2 Li- Li Bond } \\
\text { There are } 4 \times 6 \text { of these at the back corners of the facing cells. } \\
\text { These are } 25.24 \text { degrees off the axes. } \\
\text { The bond length is } 5.8253 \AA \text { when the primary bond length is } 3.043 \AA\end{array}$ & & & \\
\hline $\begin{array}{l}\text { Sigma overlap of former orbitals along axis } \\
0.90450 .9045 \text { overlap }_{s s}=0.8181 \text { overlap }_{s s}\end{array}$ & 0.0730 & & \\
\hline $\begin{array}{l}\left.\text { Fraction_bonding along axis (fraction_bonding } \text { ss }_{\text {s }}\right) \\
\text { fraction_bonding } \\
\text { ss }=\text { overlap }_{s s} /\left(1+\text { overlap }_{s s}\right)\end{array}$ & 0.0680 & & \\
\hline $\begin{array}{l}\text { Fraction_bonding exclusive of coincident bonding } \\
\text { fraction_bonding }=(1.0-(1 \text { - overlap }) /(1+1 \text { - overlap })) \text { fraction_bondingss }\end{array}$ & 0.0380 & & \\
\hline $\begin{array}{l}\text { Overlap along axis exclusive of coincident bonding } \\
\text { overlap = fraction_bonding/(1-fraction_bonding) }\end{array}$ & 0.0347 & & \\
\hline $\begin{array}{l}\text { Sum of overlap for } 4 \text { atoms along axis } \\
4 \text { overlap }\end{array}$ & 0.1435 & 0.1435 & \\
\hline $\begin{array}{l}\left.\text { Kinetic energy change associated with overlap region ( } K E_{n e t s-s}\right) \\
K E_{n e t ~ s-s}=K E_{s l+s s}-K E_{s l}-K E_{s r}\end{array}$ & 0.1814 & & \\
\hline
\end{tabular}




\begin{tabular}{|c|c|c|c|}
\hline Component & Value & $\begin{array}{l}\text { Overlap } \\
\text { addition }\end{array}$ & $\begin{array}{l}\text { Energy (eV) } \\
\text { Addition }\end{array}$ \\
\hline $\begin{array}{l}\text { Kinetic energy change of sigma orbital pairs for all } 3 \text { axes }\left(6 \mathrm{KE}_{\text {bond }}\right) \\
\left.6 \mathrm{~K} \mathrm{E}_{\text {bond }}=6 \text { (( } 4 \text { overlap) } /(1+\text { total_overlap })\right) \mathrm{KE}_{\text {net s-s }} \\
\text { Total_overlap }=4 \text { overlap }+ \text { sum of previous overlaps }\end{array}$ & 0.0831 & & 0.0831 \\
\hline $\begin{array}{l}\text { Energy to make Li } 2 s \text { orthogonal to opposite Li } 1 s^{2} \\
\left(K E_{\phi}-K E_{\phi}\right) \text { where } \phi \text { is Li } 2 s \text { made orthogonal, } \phi \text { is Li } 2 s\end{array}$ & -0.0016 & & \\
\hline $\begin{array}{l}\text { Energy to make } 24 \mathrm{Li} 2 \mathrm{~s} \text { orthogonal to opposite } 1 \mathrm{~s}^{2} \text { when not bonding } \\
\left.24 \mathrm{KE}_{\text {core_ortho }} 24\left(\mathrm{KE}_{\phi}-\mathrm{KE}_{\phi}\right) \text { (1- } 0.5\right)\end{array}$ & -0.0187 & & -0.0187 \\
\hline Net potential energy change (attractions-repulsions) & 0.0563 & & 0.0563 \\
\hline Total tertiary \#2 energy & & & 0.1207 \\
\hline \multicolumn{4}{|l|}{$\begin{array}{c}\text { Tertiary \#3 } \mathrm{Li}-\mathrm{Li} \text { Bond } \\
\text { There are } 8 \text { of these at the centers of cells sharing a corner } \\
\text { These are } 54.74 \text { degrees off the axes } \\
\text { The bond length is } 6.0855 \AA \text { when the primary bond length is } 3.043 \AA\end{array}$} \\
\hline $\begin{array}{l}\text { Sigma overlap of orbitals along axis } \\
0.57740 .5774 \text { overlap }_{\text {ss }}=0.3333 \text { overlap }_{\text {ss }}\end{array}$ & 0.0245 & & \\
\hline $\begin{array}{l}\left.\text { Fraction_bonding along axis (fraction_bonding }{ }_{s s}\right) \\
\text { fraction_bonding }_{\text {ss }}=\text { overlap }_{\mathrm{ss}} /\left(1+\text { overlap }_{\mathrm{ss}}\right)\end{array}$ & 0.0239 & & \\
\hline $\begin{array}{l}\text { Fraction_bonding exclusive of coincident bonding } \\
\text { fraction_bonding }=(1.0-(6 / 8)(1-\text { overlap }) /(1+1 \text { - overlap })) \\
\text { fraction_bondingss }\end{array}$ & 0.0151 & & \\
\hline $\begin{array}{l}\text { Overlap along axis exclusive of coincident bonding } \\
\text { overlap = fraction_bonding/(1-fraction_bonding) }\end{array}$ & 0.0153 & & \\
\hline $\begin{array}{l}\text { Sum of overlap for } 4 \text { atoms along each axis } \\
4 \text { overlap }\end{array}$ & 0.0610 & 0.0610 & \\
\hline $\begin{array}{l}\left.\text { Kinetic energy change of sigma orbital pairs for all } 3 \text { axes ( } 6 \mathrm{KE}_{\text {bond }}\right) \\
6 \mathrm{KE}_{\text {bond }}=6 \text { ( } 4 \text { overlap /(1+total_overlap)) } \mathrm{KE}_{\text {net s-s }}\end{array}$ & 0.0283 & & 0.0283 \\
\hline $\begin{array}{l}\text { Energy to make } 8 \mathrm{Li} 2 \mathrm{~s} \text { orthogonal to opposite } 1 \mathrm{~s}^{2} \text { when not bonding } \\
8 \mathrm{KE}_{\text {core_ortho }}=8\left(\mathrm{KE}_{\phi}-\mathrm{KE}_{\phi}\right)(1-0.5)\end{array}$ & -0.0035 & & -0.0035 \\
\hline Net potential energy change & 0.0120 & & 0.0120 \\
\hline Total tertiary \#3 energy & & & 0.0368 \\
\hline \multicolumn{4}{|l|}{$\begin{array}{l}\text { Tertiary \#4 Li- Li Bond } \\
\text { There are } 6 \text { of these at the center of second removed cell sharing a face } \\
\text { The bond length is } 7.0269 \AA \text { when the primary bond length is } 3.043 \AA\end{array}$} \\
\hline $\begin{array}{l}\text { Sigma overlap of orbitals along axis } \\
\text { overlapss }\end{array}$ & 0.0353 & & \\
\hline $\begin{array}{l}\text { Overlap along axis excluding coincident bonding } \\
\text { overlap = fraction_bonding/(1-fraction_bonding) }\end{array}$ & 0.0175 & 0.0175 & \\
\hline $\begin{array}{l}\left.\text { Kinetic energy change of sigma orbital pairs for all } 3 \text { axes ( } 6 \mathrm{KE}_{\text {bond }}\right) \\
\left.6 \mathrm{KE}_{\text {bond }}=6 \text { (overlap } /(1+\text { total_overlap })\right) K E_{\text {net s-s }}\end{array}$ & 0.0038 & & 0.0038 \\
\hline
\end{tabular}




\begin{tabular}{|c|c|c|c|}
\hline Component & Value & $\begin{array}{l}\text { Overlap } \\
\text { addition }\end{array}$ & $\begin{array}{l}\text { Energy (eV } \\
\text { Addition }\end{array}$ \\
\hline $\begin{array}{l}\text { Energy to make } 6 \mathrm{Li} 2 \mathrm{~s} \text { orthogonal to opposite } 1 \mathrm{~s}^{2} \text { when not bonding } \\
6 \mathrm{KE}_{\text {core_ortho }}=6\left(\mathrm{KE}_{\phi}-\mathrm{KE}_{\phi}\right)(1-0.5)\end{array}$ & -0.0003 & & -0.0003 \\
\hline Net potential energy change & 0.0028 & & 0.0028 \\
\hline Total tertiary \#4 energy & & & 0.0063 \\
\hline
\end{tabular}

$$
\text { Tertiary \#5 Li - Li Bond }
$$

There are $4 \times 6$ of these at the back corner of cells sharing edge

These are 46.51 degrees off the Cartesian axes

The bond length is $7.6573 \AA$ when the primary bond length is $3.043 \AA$

\begin{tabular}{|c|c|c|}
\hline Overlap along axis excluding coincident bonding & 0.0199 & 0.0199 \\
\hline $\begin{array}{l}\left.\text { Kinetic energy change of sigma orbital pairs for all } 3 \text { axes (6 KE } \mathrm{K}_{\text {bond }}\right) \\
\left.6 \mathrm{KE}_{\text {bond }}=6 \text { (overlap } /(1+\text { total_overlap })\right) \mathrm{KE}_{\text {net s-s }}\end{array}$ & 0.0025 & 0.0025 \\
\hline $\begin{array}{l}\text { Energy to make } 48 \mathrm{Li} 2 \mathrm{~s} \text { orthogonal to opposite } 1 \mathrm{~s}^{2} \text { when not bonding } \\
24 \mathrm{KE}_{\text {core_ortho }}=24\left(\mathrm{KE}_{\phi}-\mathrm{KE}_{\phi}\right)(1-0.5)\end{array}$ & -0.0003 & -0.0003 \\
\hline Net potential energy change & 0.0051 & 0.0051 \\
\hline Total tertiary \#5 energy & & 0.0073 \\
\hline
\end{tabular}

Tertiary \#6 Li- Li Bond

There are $4 \times 6$ of these at the facing back corner of second removed cells

at 15.79 degrees off the Cartesian axes and

there are 8 at the center of second removed cells sharing corner

at 54.74 degrees off the Cartesian axes.

The bond length is $9.1282 \AA$ when the primary bond length is $3.043 \AA$

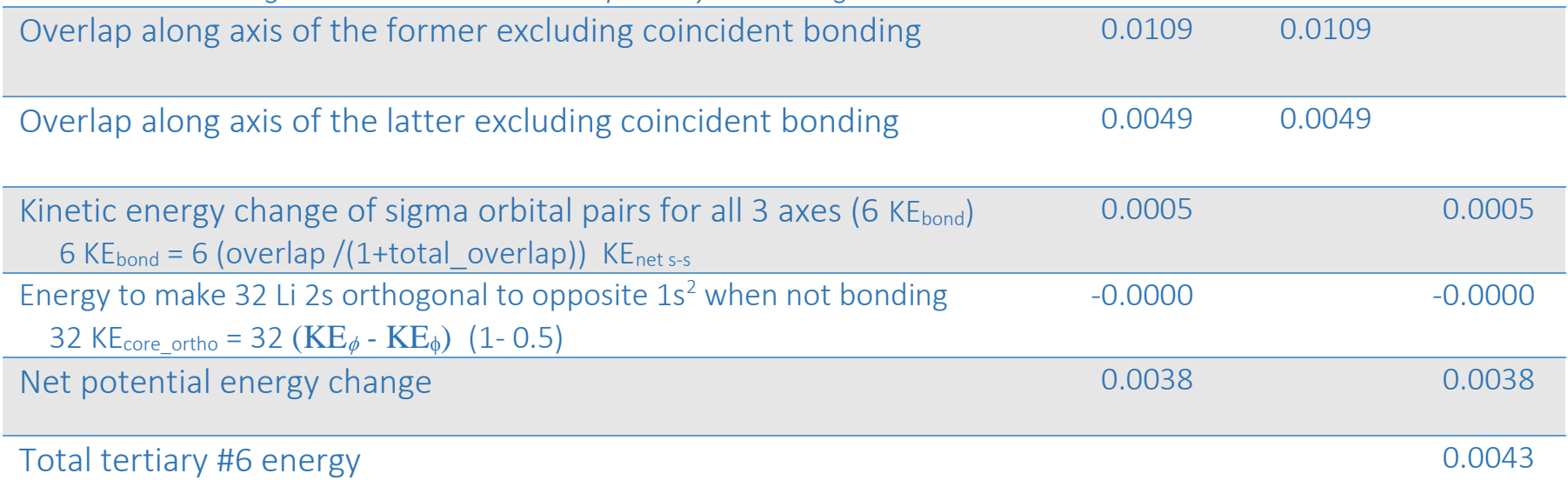

Tertiary \#7 Li - Li Bond

There are 6 of these at the center of the third removed cell

The bond length is $10.54 \AA$ when the primary bond length is $3.043 \AA$

$\begin{array}{lll}\text { Overlap along axis excluding coincident bonding } & 0.0008 & 0.0008\end{array}$

$\begin{array}{lll}\left.\text { Kinetic energy change of sigma orbital pairs for all } 3 \text { axes ( } 6 \mathrm{KE}_{\text {bond }}\right) & 0.0000 & 0.0000\end{array}$ $6 \mathrm{KE}_{\text {bond }}=6$ (overlap $/\left(1+\right.$ total_overlap)) $\mathrm{KE}_{\text {net s-s }}$ 


\begin{tabular}{|c|c|c|c|}
\hline Component & Value & $\begin{array}{l}\text { Overlap } \\
\text { addition }\end{array}$ & $\begin{array}{l}\text { Energy (eV) } \\
\text { Addition }\end{array}$ \\
\hline $\begin{array}{l}\text { Energy to make } 6 \mathrm{Li} 2 \mathrm{~s} \text { orthogonal to opposite } 1 \mathrm{~s}^{2} \text { when not bonding } \\
6 \mathrm{KE}_{\text {core_ortho }}=6\left(\mathrm{KE}_{\phi}-\mathrm{KE}_{\phi}\right)(1-0.5)\end{array}$ & -0.0000 & & -0.0000 \\
\hline Net potential energy change & 0.0007 & & 0.0007 \\
\hline Total tertiary \#7 energy & & & 0.0007 \\
\hline Totals & & 0.9931 & 1.7136 \\
\hline
\end{tabular}

\section{B. Diamond}

The results of an orbital exchange calculation of diamond were presented in reference 1 . The bonding hybrid orbitals in diamond are of the form $\phi=f_{s} 2 s+f p_{b} 2 p_{z}$. The coefficients $\mathrm{fs}_{\mathrm{b}}=\mathrm{fp}_{\mathrm{b}}=0.5$. This " $\mathrm{sp}$ " hybrid orbital overlaps completely (overlap=1.0) along one side of the bond axis (No overlaps on the axes perpendicular to the bond axis.). In the opposite direction on bond axis, the bonding orbital is an "s-p"'(s minus $p$ ) orbital of the form $\phi=f s_{b} 2 s-f p_{b} 2 p_{z}$. The overlap of this s-p orbital with the resultant components of the s-p orbitals of the opposite $3 \mathrm{C}$ atoms is virtually zero.

The overlap of the primary component of the sp to sp bond is 0.7960 . The overlap of the primary component of the s-p to s-p bond in the opposite direction is 0.0014 . Since there are secondary, tertiary, etc. contributions to the overlap along the positive direction, the total overlap in the positive direction reaches 1.0. The secondary, tertiary, etc. contributions along the opposite direction are negligible. The ratio of the overlap in the positive direction to that in the opposite negative direction is 1.0 to 0.0014 .

Although both diamond and Li metal reach the bonding limit of overlap=1.0, they do it in very different ways. In Li metal, the sigma bonding orbital bonds in the same manner along all axes and in both directions on each axis. The same $2 \mathrm{~s}$ bonding orbital is common to bonding along all 3 axes. In diamond, the sigma bonding orbital bonds only in one direction along the primary bond axis. In diamond, electrons are not free to move from one $\mathrm{C}$ to the next $\mathrm{C}$.

\section{Beryllium Metal}

Beryllium metal (the normal form) has the hexagonal closed packed structure ${ }^{8}$. Wells ${ }^{9}$ and Decker ${ }^{10}$, among many others, provide diagrams of this structure. In Be metal six of the nearest neighbors have a slightly different bond length $(0.04 \AA)$ than the other six ${ }^{11}$. In this work a uniform bond length is assumed.

Be has the configuration $1 s^{2} 2 s^{2}$. One of the 2 s electrons has to be promoted to $2 p$ to meet the valence orthogonality requirement (See Section II.C.2 of reference 1). The bonding configuration is $1 s^{2} 2 s 2 p$. The $2 p$ aligns itself randomly along one of the three Cartesian axes. Therefore, each Be has an sp bonding orbital aligned randomly along one of the three axes and a $\mathrm{s}$ bonding orbital aligned along the other two. The sp to sp overlap takes the form: 
$\begin{aligned} \text { overlap }_{\mathrm{sp}-\mathrm{sp}=} & 0.25 \text { overlap }_{\mathrm{s}-\mathrm{s}}+\cos \theta \cos \theta 0.25 \text { overlap }_{\mathrm{pz}-\mathrm{pz}}+ \\ & \cos \theta 0.25 \text { overlap }_{\mathrm{pz}-\mathrm{s}}+\cos \theta 0.25 \text { overlap }_{\mathrm{s}-\mathrm{pz}}\end{aligned}$

The $\mathrm{sp}$ to $\mathrm{s}, \mathrm{s}$ to $\mathrm{sp}$, and $\mathrm{s}$ to $\mathrm{s}$ overlaps are

overlap $_{\text {sp-s }}=0.5$ overlap $_{\mathrm{s}-\mathrm{s}}+\cos \theta 0.5$ overlap $_{\mathrm{pz}-\mathrm{s}}$,

overlap $_{\mathrm{s} \text {-sp }}=0.5$ overlap $_{\mathrm{s}-\mathrm{s}}+\cos \theta 0.5$ overlap $_{\mathrm{s}-\mathrm{pz}}$,

and

overlap $_{\mathrm{s}-\mathrm{s}}=$ overlap $_{\mathrm{s}-\mathrm{s}}$.

The angle $\theta$ is the angle between the major $\mathrm{z}$ axis and the bonding atom. For the nearest neighbors, $\cos \theta=0.8165$. (The $\mathrm{z}$ axis is perpendicular to the plane of 6 nearest neighbors.)

Since there is an sp orbital along one axis and an s orbital along the other two, the overall overlap is:

$$
\begin{aligned}
& \text { overlap }=\cos \theta \cos \theta\left(2 / 32 / 3 \text { overlap }_{\text {sp-sp }}+2 / 31 / 3 \text { overlap }_{\text {sp-s }}+\right. \\
& 1 / 32 / 3 \text { overlap }_{\text {s-sp }}+1 / 31 / 3 \text { overlap }_{\text {s-s }} \text { ). }
\end{aligned}
$$

The presence of the $p_{z}$ orbital has a very significant impact on the directionality of the bonding orbital. At $2.249 \AA$, the overlap of the 3 primary bonds is 0.511 . In the opposite direction, substituting s-p orbitals for the sp components of the bonding orbital gives a primary overlap of 0.159 . Although this difference in overlap (primary overlap of 0.511 vs. 0.159 ) indicates substantial directionality, it is much less than that exhibited by the insulator, diamond (overlap of 1.0 vs. 0.0014). (It should be noted that these overlap numbers are not directly proportional to expected conductivity.)

Group 1 metals (alkali metals) with ns configurations, generally exhibit higher electrical conductivity than group 2 metals (divalent metals) with $\mathrm{ns}^{2}$ configurations. Decker ${ }^{12}$ provides a figure showing the relative conductivities of these metals. In general, the necessity for metals with an $n s^{2}$ configuration to take on the $n s \mathrm{np}$ configuration to bond appears to cause these metals to have lower electrical conductivity.

\section{Graphite}

The results of an orbital exchange calculation of graphite were presented in reference 1 . Graphite consists of layers of a repeating planar array of 3-coodinate carbon atoms. Wells ${ }^{13}$, among many others, provides a figure illustrating the structure. Carbon has the configuration $1 s^{2} 2 s^{2} 2 p^{2}$. To meet the valence orthogonality requirement, one 2 s electron must be promoted to $2 \mathrm{p}$ to the extent that any of the three carbon bonds are "not bonding" (i.e. 1.0-0.5 0.5 0.5 = $0.125)$. This leads to a bonding configuration of $1 \mathrm{~s}^{2} 2 \mathrm{~s}^{1.125} 2 \mathrm{p}_{\mathrm{z}} 2 \mathrm{p}_{\mathrm{xy}}{ }^{2} 2 \mathrm{p}_{\pi}{ }^{0.875}$.

Since, in graphite, there is residual $2 \mathrm{~s}$ in excess of 1.0 , there is opportunity for a limited amount of dual bonding (See Section II.F in reference 1.). This small amount of $s$ to $s$ bonding is omnidirectional and gives rise to some passage of electrons and limited conductivity. The primary overlap of these $2 \mathrm{~s}$ orbitals at $1.421 \AA$ is 0.0167 . A larger contribution to conductivity comes from pi bonding. Pi bonding is not directional in the basal plane. A single primary pi overlap at $1.421 \AA$ is 0.2287 . 
As in diamond, the graphite hybrid bonding orbital has the form $\phi=\mathrm{fs}_{\mathrm{b}} 2 \mathrm{~s}+\mathrm{fp}_{\mathrm{b}} 2 \mathrm{p}_{\mathrm{z}}$. However, since graphite is 3 (vs. 4 for diamond) coordinate, there is more 2 s character available for each bond. In graphite, $\mathrm{fs}_{\mathrm{b}} \mathrm{fs}_{\mathrm{b}}=0.6667 \pm 0.0083$ (Bonding orbitals take on as much $\mathrm{s}$ character as possible as this leads to shorter bonds). As in diamond, the opposite s-p orbitals overlap very little. Sigma hybrid orbital bonding does not contribute significantly to graphite conductivity.

\section{CONCLUSION}

The bond length and bond energies calculated for lithium and beryllium metal using the orbital exchange method are in good agreement with the observed values. The calculated bond energies are accurate to $0.2 \mathrm{eV}$ or better and bond lengths to $0.02 \AA$. Comparison of the chemical bonds in metals with the bonds in an insulator such as diamond strongly suggest that electrical conductivity (in the absence of atomic vibrations or crystal dislocations) is determined by the directionality of the chemical bonds. Those materials whose bonding orbitals are common to bonds in all directions (i.e. omnidirectional) are conductors. Those materials whose bonding orbitals are specific to a bond in one direction are insulators. Those materials whose bonding orbitals are not completely omnidirectional nor directional are semiconductors.

Although silicon ( $\mathrm{Si}$ ) and germanium $(\mathrm{Ge})$ have not been investigated in this work, one can speculate about the nature of bonding in these semiconductors. Since both $\mathrm{Si}$ and Ge have diamond structures ${ }^{14}$ one might expect these to be insulators as is diamond. However, as atomic numbers rise the energy difference between ns and $\mathrm{np}$ atomic orbitals increases. This is accompanied by a concomitant rise in the difference in radii between the ns and np atomic orbitals. The formation of a hybrid orbital requires that the radii of the component orbitals be reasonably close. Consequently, the directionality of hybrid orbitals decreases as the atomic number increases. In the limit of very high atomic number, there results no hybrid orbital, only ns and np orbitals. Apparently, Si and Ge are semiconductors because their bonding orbitals are not nearly as directional as those in diamond.

\footnotetext{
${ }^{1}$ P.B. Merrithew, ChemRxiv. [Preprint] https://doi.org/10.26434/chemRxiv.13049927 (2020)

${ }^{2}$ W.E. Duncanson and C.A. Coulson, Proc.Roy.Soc. (Edinburgh), 62, 37 (1944).

${ }^{3}$ W.M. Hayes, Editor in Chief, CRC Handbook of Chemistry and Physics, Section 5, CRC Press (2014).

${ }^{4}$ W.M. Hayes, Editor in Chief, CRC Handbook of Chemistry and Physics, Section 12, CRC Press (2014).

${ }^{5}$ A.F. Wells, Structural Inorganic Chemistry 5th Edition, pp1281and1285, Oxford University Press (1984).

${ }^{6}$ A.F. Wells, Structural Inorganic Chemistry $5^{\text {th }}$ Edition, pp 142, Oxford University Press (1984).

${ }^{7}$ A. Sommerfeld, Z.Physik , 47, 1 (1928).

${ }^{8}$ A.F. Wells, Structural Inorganic Chemistry $5^{\text {th }}$ Edition, pp1285, Oxford University Press (1984).

${ }^{9}$ A.F. Wells, Structural Inorganic Chemistry $5^{\text {th }}$ Edition, pp 155, Oxford University Press (1984).

${ }^{10}$ A.J. Decker, Solid State Physics, pp61, Prentice-Hall (1963).

${ }^{11}$ A.F. Wells, Structural Inorganic Chemistry $5^{\text {th }}$ Edition, pp1286, Oxford University Press (1984).
} 
${ }^{12}$ A.J. Decker, Solid State Physics, pp286, Prentice-Hall (1963).

${ }^{13}$ A.F. Wells, Structural Inorganic Chemistry $5^{\text {th }}$ Edition, pp 922, Oxford University Press (1984).

${ }^{14}$ A.F. Wells, Structural Inorganic Chemistry $5^{\text {th }}$ Edition, pp 985, Oxford University Press (1984). 